SHORT REPORT

\title{
Measured versus reported parental height
}

F Cizmecioglu, A Doherty, W F Paterson, D Young, M D C Donaldson

Background: Parental height data are essential in the assessment of linear growth in children. A number of studies have documented inaccuracy in self-reported adult height.

Aims: To determine whether there is a tendency for men to overestimate and women to underestimate their height.

Methods: Heights of parents of children attending outpatient clinics were measured $(\mathrm{MHt})$ and compared with reported heights (RHt).

Results: Two hundred parents (100 males; 100 females), mean (range) age 37.8 (20.8-69.3) years, were measured. Males overestimated height, with mean (SD) RHt-MHt 1.09 $(1.96) \mathrm{cm}$, while females reported height relatively accurately, with $\mathrm{RHt}-\mathrm{MHt}-0.09(2.37) \mathrm{cm}$.

Conclusions: The hypothesis that males overestimate height is confirmed. While the hypothesis that women underestimate is not supported, we recommend accurate measurement of both parents, given the considerable degree of individual variation in $\mathrm{RHt}-\mathrm{MHt}$ for both sexes.

$\mathrm{D}$ etermination of genetic height potential, based on parental heights, is fundamental to the evaluation of growth in children. The child's current height centile position is compared with the mid-parental height (MPH) centile and target range (MPH $\pm 2 \mathrm{SD}$ ), which are plotted on the growth chart. A child whose height centile falls outside the parental target range is more likely to have a growth disorder. Plotting a child's MPH and target range is standard practice in specialist paediatric growth and endocrinology clinics. However, genetic height potential is assessed less frequently in general paediatric practice. While the importance of obtaining accurate measured parental heights is recognised, it is easier and quicker to record reported heights, and often only one parent accompanies the child to clinic.

At the Royal Hospital for Sick Children in Glasgow, we have noticed a discrepancy between measured and reported heights and have formed the impression that men tend to overestimate their height and women to underestimate. This observational study was carried out to test these hypotheses and estimate the size of the discrepancy between RHt and MHt in both sexes.

\section{METHODS}

Following approval by the Yorkhill Ethics Committee, parents of children attending non-endocrine outpatient clinics were recruited and informed consent obtained. A short interview was conducted during which date of birth, gender, and selfreported height (and source) were recorded. Each participant was then measured by a single observer (FC), using a Harpenden stadiometer; standard UK measurement technique and height were recorded to the nearest $0.1 \mathrm{~cm}$. FC's measurement technique was validated by inter-observer comparison with an experienced measurer (AD). Twenty paediatric outpatients were measured consecutively by FC and $\mathrm{AD}$ and their heights compared: the mean inter-observer difference was less than $0.3 \mathrm{~cm}$.

All reported heights were converted to metric units and the differences between reported and measured heights were analysed using a general linear model. Possible predictors included in the model were: gender, age, and actual measured height. Statistical analyses were done using MINITAB (version 13) and results are displayed descriptively with 95\% confidence intervals (CI) for the magnitude of the effect.

\section{RESULTS}

Two hundred parents (100 males; 100 females), mean age 37.8 years (range 20.8-69.3) participated. No subject who
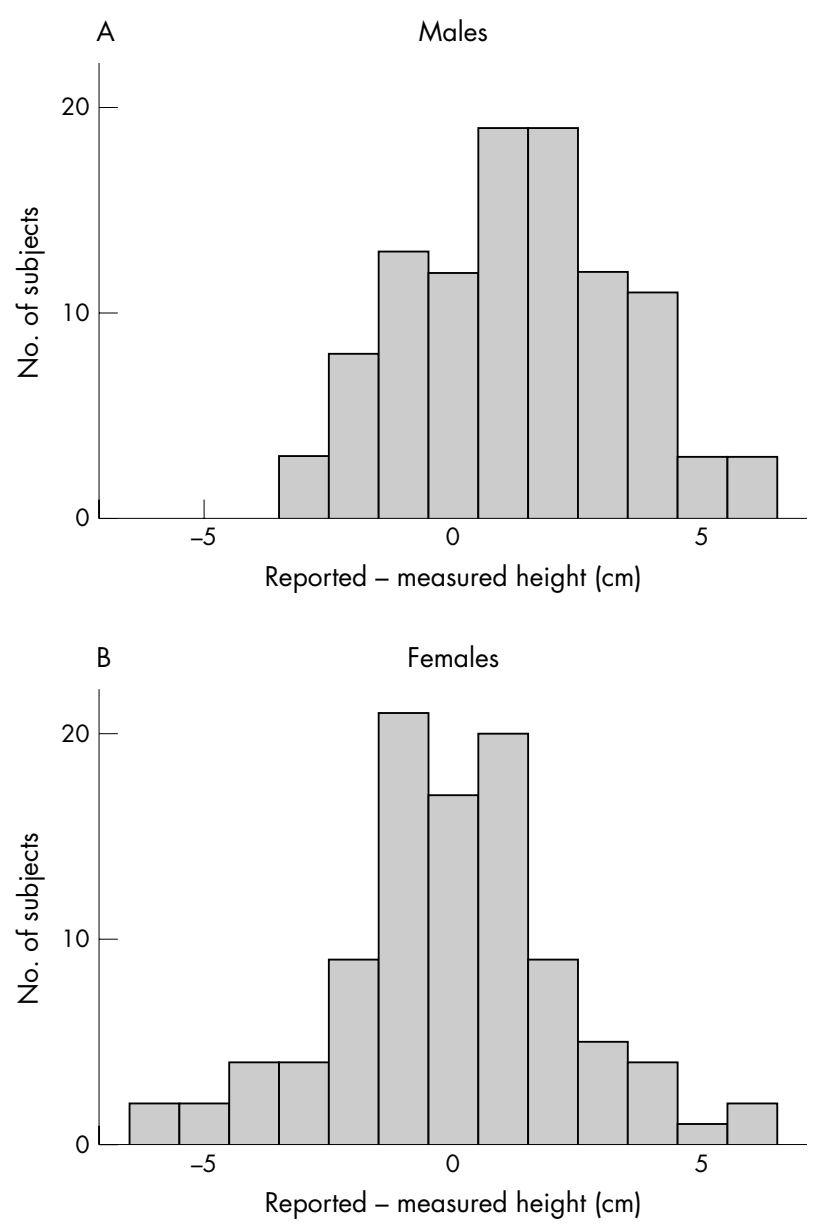

Figure 1 Histograms illustrating the difference between reported and measured height in (A) 100 adult males and (B) 100 adult females. RHt$\mathrm{MHt}$ is indicated on the $\mathrm{x}$-axis, with " $\mathrm{O}$ " indicating no difference, a negative value indicating underestimation, and a positive value indicating overestimation of height. A wide spread of values is evident for both sexes, with a clear shift towards overestimation of height in males. 


\begin{tabular}{|c|c|c|c|c|c|}
\hline \multirow[b]{2}{*}{ Gender } & \multicolumn{5}{|c|}{ Reported - measured height $(\mathrm{cm})$} \\
\hline & Mean & Median & SD & Range & $95 \% \mathrm{Cl}$ \\
\hline $\begin{array}{l}\text { Male } \\
\text { Female }\end{array}$ & $\begin{array}{r}1.09 \\
-0.09\end{array}$ & $\begin{array}{r}1.25 \\
-0.10\end{array}$ & $\begin{array}{l}1.96 \\
2.37\end{array}$ & $\begin{array}{l}-3.3 \text { to } 5.2 \\
-6.2 \text { to } 6.4\end{array}$ & $\begin{array}{r}0.698 \text { to } 1.476 \\
-0.564 \text { to } 0.376\end{array}$ \\
\hline
\end{tabular}

was invited to take part, refused. Eighty three subjects guessed RHt while 117 had been measured previously-74 in a medical setting, 37 in a non-medical setting, 6 did not recall where.

Of the 200 participants, 192 reported their height in feet and inches, to the nearest half inch. The remaining 8 reported their height in centimetres-all to the nearest centimetre.

Gender and age were significant predictors of the difference between RHt and MHt. On average, males overestimated height while females reported their height relatively accurately, as detailed in table 1 . However, there was a wide spread of values for both sexes, as illustrated in fig 1. Overall there was a small positive correlation between age and RHt-MHt $(\mathrm{r}=0.251, \mathrm{p}<0.001)$.

Comparison of subjects who had been measured previously with those who guessed their height revealed more accurate reporting by the latter group: mean (SD), range RHt-MHt $0.81(2.03),-4.8$ to $5.2 \mathrm{~cm}$ and $0.05(2.47),-6.2$ to $6.4 \mathrm{~cm}$, respectively. Again, however, there was a wide spread of values in each group.

\section{DISCUSSION}

The results of this study support our hypothesis that men tend to overestimate their height. In contrast, on average women estimated their height relatively accurately. However, there was considerable individual variation, with 13\% of women and $27 \%$ of men overestimating their height by $2.5 \mathrm{~cm}$ ( 1 inch) or more and $18 \%$ of women and $4 \%$ of men underestimating by the same amount.

Metric units of measurement have been taught in UK schools since 1974 and are used exclusively by health professionals and the clothing industry. Despite this, most subjects reported their height in feet and inches, to the nearest half inch $(1.3 \mathrm{~cm})$. In contrast, height was measured to the nearest $0.1 \mathrm{~cm}$. Clearly, this discrepancy between units of measurement may account for some of the difference between measured and reported height.

Surprisingly, we found that height was reported more accurately by subjects who guessed their height than by those who had been measured before. This may reflect a poor standard of measurement in both medical and non-medical settings.

While using parental heights to ascertain whether a child's height centile is consistent with genetic expectations is widely used, it is important to recognise the limitations of this practice. In particular, adjustment should be made for regression to the mean-that is, the tendency for children of especially short or tall parents to be relatively less short or tall. ${ }^{1}$

There have been a considerable number of studies investigating the accuracy of self-reported heights, with varying conclusions. For example, women overestimated their height in 21 of 26 studies reviewed by Engstrom and colleagues. $^{2}$ In keeping with the present study, the mean differences between reported and measured heights were small but there was significant individual variation. Both men and women ( $\mathrm{n}=4808$; age range $35-76$ years $)$ in the Oxford cohort of the European Prospective Investigation into Cancer and Nutrition (EPIC) overestimated their height, the discrepancy being greater in men than in women (mean (SD) $1.23(2.57)$ versus $0.6(2.68) \mathrm{cm}) .^{3}$ As in the current study, height difference was positively associated with age in both sexes. However, in contrast to our study, in men there was a negative association with actual height (that is, shorter men overestimated their height more). Interestingly, in a Scottish study based on a random population sample, both men and women ( $\mathrm{n}=1836$; age range 25-64 years) underestimated their height by a mean (SD) of $1.3(2.50)$ and $1.7(2.37) \mathrm{cm}$, respectively. ${ }^{4}$

Despite the differences between the present study and previous investigations in terms of over- or underestimation of height, a common feature of all studies, is the wide individual variation between reported and measured heights in both sexes. This reinforces the need for accurate measurement of both mother and father in paediatric clinical practice. We recommend that efforts should be made to measure both parents at the earliest opportunity and record their heights in the child health record.

\section{ACKNOWLEDGEMENTS}

We would like to thank the European Society for Paediatric Endocrinology for funding Dr Filiz Cizmecioglu's six month fellowship in Scotland and all the parents who agreed to participate in this study.

\section{Authors' affiliations}

F Cizmecioglu, Kocaeli University, Paediatric Endocrinology \& Diabetes Department, Turkey

A Doherty, Outpatient Department, Royal Hospital for Sick Children, Glasgow, UK

W F Paterson, M D C Donaldson, Department of Child Health, Royal Hospital for Sick Children, Glasgow, UK

D Young, Research and Development Office, Royal Hospital for Sick Children, Glasgow, UK

Competing interests: none declared

Correspondence to: Ms W Paterson, Department of Child Health, Royal Hospital for Sick Children, Yorkhill, Glasgow G3 8SJ, UK; gcl354@ clinmed.gla.ac.uk

Accepted 1 May 2005

\section{REFERENCES}

1 Wright CM, Cheetham TD. The strengths and limitations of parental heights as a predictor of attained height. Arch Dis Child 1999;81:257-60.

2 Engstrom JL, Paterson SA, Doherty A, et al. Accuracy of self-reported height and weight in women: an integrative review of the literature. J Midwifery Womens Health 2003;48:338-45.

3 Spencer EA, Appleby PN, Davey GK, et al. Validity of self-reported height and weight in 4808 EPIC-Oxford participants. Public Health Nutrition 2002;5:561-5

4 Bolton-Smith C, Woodward M, Tunstall-Pedoe H, et al. Accuracy of the estimated prevalence of obesity from self reported height and weight in an adult Scottish population. J Epidemiol Community Health 2000;54:143-8. 